Research article

\title{
Physiological responses of carp (Cyprinus carpio L.) to dietary exposure to zearalenone (ZEN)
}

\author{
Constanze Pietsch *, Ranka Junge \\ Zurich University of Applied Sciences (ZHAW), Institute of Natural Resource Sciences (IUNR), Gruental, P.O. Box, CH-8820 Waedenswil, Switzerland
}

\section{A R T I C L E I N F O}

\section{Article history:}

Received 21 March 2016

Received in revised form 30 May 2016

Accepted 15 June 2016

Available online 25 June 2016

\section{Keywords:}

Carp

Mycotoxin

Physiological stress

Metabolic costs

Aquaculture

\begin{abstract}
A B S T R A C T
Zearalenone (ZEN) is a frequent contaminant of animal feeds, but systemic effects on fish and possible metabolic costs have not yet been investigated. In order to fill this gap a feeding trial with juvenile carp was conducted. The fish were fed ZEN-contaminated diets at three concentrations (low: $332 \mu \mathrm{g} \mathrm{kg}^{-1}$, medium: $621 \mu \mathrm{g} \mathrm{kg}{ }^{-1}$, and high: $797 \mu \mathrm{g} \mathrm{kg}^{-1}$ final feed, respectively) for four weeks. Possible reversible effects of ZEN were evaluated by feeding an additional group with the mycotoxin for four weeks period and the uncontaminated diet for further two weeks. After that possible ZEN effects on enzyme activities in kidney, spleen, liver and muscle tissue were investigated to get an organism-wide aspect of ZEN effects. Most organs appeared to (over)compensate ZEN effects during the exposure to this mycotoxin, which caused metabolic costs. Oxygen consumption increased in fish treated with the two higher ZEN concentrations via the diet. The differences between the treatments persisted also after the recovery phase of two weeks. Thus, the present study provided evidence of effects of ZEN on carbohydrate metabolism, lipid peroxidation in organs and metabolic oxygen demand. This is the first evidence for increased metabolic costs in a fish species due to exposure to the mycotoxin ZEN.
\end{abstract}

(c) 2016 Elsevier Inc. All rights reserved.

\section{Introduction}

The knowledge on the occurrence of zearalenone (ZEN) in animal feed including fish feeds is increasing (Santos et al., 2010; Pietsch et al., 2013; Greco et al., 2015). In parallel, research on the toxicological effects of ZEN is accumulating. Oral uptake of ZEN has been found to cause hepatotoxic, immunotoxic and genotoxic effects in fish (Pietsch et al., 2015a, 2015b). Furthermore, haematological and reproductive responses were investigated (Pietsch et al., 2015a; Johns et al., 2009; Schwartz et al., 2010; Woźny et al., 2012; Bakos et al., 2013). In contrast, metabolic consequences in terms of increased energy expenditure due to ZEN exposure have not yet been shown.

Fish need energy for meeting the demands of physiological maintenance, growth, and reproduction. However, exposure to chemicals is known to cause physiological stress which in turn increases metabolic costs (Beyers et al., 1999). If additional costs due to damage from chemical exposure are imposed upon fish, they must reallocate energy expenditures in order to repair the affected system. While it has been shown that ZEN does not influence feed conversion and growth rates of fish including carp (Pietsch et al., 2015a; Döll et al., 2011), effects on the immune system and hematological parameters appear to be a major action of this mycotoxin in carp (Pietsch et al., 2015a, 2015b). The estrogenic potential of ZEN was discussed, however studies on

\footnotetext{
* Corresponding author.

E-mail address: constanze.pietsch@zhaw.ch (C. Pietsch).
}

this aspect yielded contradictive results depending on the fish species, the life stage, the route of exposure and the exposure dose (Pietsch et al., 2015a; Johns et al., 2009; Schwartz et al., 2010; Bakos et al., 2013).

Irrespective of the chemicals mode of action, the physiological systems of organisms compensate for specific effects from exposure to the contaminant. Hence, homeostatic mechanisms are induced in order to reestablish equilibrium. This may affect appetite and can cause a loss of equilibrium, and behavioral changes in fish (Beyers et al., 1999; Weis, 2014). When physiological adaptation to a chemical stressor has been accomplished, the fish enter the stage of resistance. This stage may be associated with increased metabolic rates, since the mechanisms necessary for compensation for the effects of a chemical stressor become part of the normal cost of living for exposed animals. Many fishes are not evolutionarily adapted to the elevated energetic costs of compensating for anthropogenic stressors and this probably also includes the effects due exposure to mycotoxins. Thus, for a while contaminant effects can be compensated for, but if a stressor is of sufficient magnitude and the fish are exposed for a sufficient period of time, they enter the third stage of adaptation: the phase of exhaustion. This includes cumulative effects of long-term exposure to stressors which eventually lead to premature death of the individual. Chemical stressors may, thus, result in mortality since the physiological systems that are needed for compensating for toxic effects become exhausted and stop functioning (Schulte, 2014).

The investigation of metabolic rates may indicate the physiological status of an animal, for example, during adaptation to a chemical 
stressor. While metabolic rates can accurately be measured by direct calorimetry (van Ginneken and van den Thillart, 2009) their measurement by swimming and resting respirometry is more common (Roche et al., 2013). The latter methods estimate metabolic rates of aquatic organisms from measurements of oxygen consumption rates $\left(\mathrm{MO}_{2}\right)$ which can more easily be measured in water than small changes of temperature due to the activity of aquatic organisms in calorimeters.

Since previous studies indicated hematological, genotoxic, and immunological effects of ZEN in carp (Pietsch et al., 2015a, 2015b), the present study investigated the effects of ZEN on organ condition more closely and measured oxygen consumption rates. This was necessary to show that systemic impact of ZEN on carp is paralleled by an influence on metabolic rates.

\section{Materials and methods}

\subsection{Chemicals}

All chemicals were obtained from Sigma (Buchs, Switzerland) unless indicated otherwise.

\subsection{Preparation of feeds}

Experimental diets without inclusion of cereal ingredients have been prepared to exclude contamination of the final feed with natural Fusarium mycotoxins. Feed production and their experimental contamination with zearalenon (ZEN, purity $>99 \%$, purchased from SigmaAldrich, Switzerland, lot-no. 041M4054V) have been described previously (Pietsch et al., 2015a). The final feeds showed three different ZEN concentrations: low medium and high $\left(332 \mu \mathrm{g} \mathrm{kg}^{-1}, 621 \mu \mathrm{g} \mathrm{kg}^{-1}\right.$ and $797 \mu \mathrm{g} \mathrm{kg}^{-1}$ final feed, respectively) whereas the control diet was not supplied with ZEN and consequently did not show detectable ZEN levels measured according to the method of the "Verband Deutscher Landwirtschaftlicher Untersuchungs- und Forschungsanstalten" (VDLUFA-Methodenbuch III, 2006) using HPLC with fluorescence detection after a clean-up with IAC (immunoaffinity column, ZearalaTest, Vicam, Klaus Ruttmann, Hamburg, Germany). The detection limit was $2 \mu \mathrm{g} \mathrm{kg}^{-1}$ and mean recovery was approximately $79 \%$. To exclude malnutrition in experimental groups the final diets were isonitrogenous and isocaloric (Pietsch et al., 2015a), and were stored at $4{ }^{\circ} \mathrm{C}$ until use.

\subsection{Exposure of fish}

Juvenile carp were fed the experimental diets for four weeks at a feeding intensity of $3 \%$ in a flow-through system. The rearing conditions of this feeding trial have been described previously (Pietsch et al., 2015a). Thereafter, 6 fish per feeding group from two tanks were sampled. The recovery from ZEN feeding was investigated by feeding the remaining two tanks per feeding group with the uncontaminated diet for additional two weeks before the final sampling. All experimental procedures were approved by the Cantonal veterinarian authorities of BaselStadt (Switzerland) under the permission number 2410.

\subsection{Lipid peroxidation assay and LDH activity measurements}

Tissue samples were homogenized in 19 volumes PBS containing $0.1 \%(w / v)$ butylated hydroxytoluene (BHT) using an UltraThurrax (IKA Werke, Staufen, Germany) for $10 \mathrm{~s}$, and centrifuged for $10 \mathrm{~min}$ at $10^{\circ} 000 \mathrm{~g}$ at $4{ }^{\circ} \mathrm{C}$ (Centrifuge 5415R, Eppendorf, Basel, Switzerland). The supernatant was used for the TBARs assay according to Rau et al. (2004) with the following modifications. A volume of $40 \mu \mathrm{l}$ supernatant was mixed with $200 \mu \mathrm{l}$ TBARs solution (Holt et al., 1986) containing $3.75 \mathrm{mg} \mathrm{ml}^{-1}$ thiobarbituric acid (TBA), 20\% (w/v) trichloric acid (TCA), $9.1 \mu \mathrm{ml}^{-1}$ hydrochloric acid (37\%), 0.06\% (w/v) BHT, and $866.9 \mu \mathrm{l}$ distilled water. Thereafter, samples were incubated at $70{ }^{\circ} \mathrm{C}$ for $90 \mathrm{~min}$, cooled to room temperature, and centrifuged at $16^{\circ} 000 \mathrm{~g}$ for $15 \mathrm{~min}$ at room temperature. In parallel, standards containing 0 to $3200 \mathrm{nM}$ malondialdehyde (MDA) were prepared. Optical densities of all samples on microtitre plates (Rotilabo®, Carl Roth AG, Karlsruhe, Germany) were read at $532 \mathrm{~nm}$ (Infinite M200, Tecan Group Ltd., Männedorf, Switzerland). Aliquots of the tissue homogenates were also used for the lactate dehydrogenase (LDH) assay and protein determinations. The latter were conducted using the bicinchoninic acid (BCA) assay (Sigma) according to the manufacturer's protocol. The activity of LDH in tissue homogenates and serum samples was measured according to Bergmeyer (1974a). In short, $164 \mu \mathrm{l}$ NADH solution [0.244 $\mathrm{mmol} \mathrm{l}^{-1}$ in Tris- $\mathrm{NaCl}$ solution (Tris, $81.3 \mathrm{mmol} \mathrm{l}^{-1}$; $\mathrm{NaCl}$, $203.2 \mathrm{mmol} \mathrm{l}^{-1} \mathrm{pH} 7.2$ )] were mixed with $33 \mu \mathrm{l}$ pyruvate solution ( $9.76 \mathrm{mmol} \mathrm{l}^{-1}$ in Tris- $\mathrm{NaCl}$ solution). The reaction was started by addition of $20 \mu \mathrm{l}$ sample and absorption decrease at a wavelength of $339 \mathrm{~nm}$ was recorded for 10 min (Infinite M200, Tecan Group Ltd., Männedorf, Switzerland).

\subsection{Preparation of serum samples and determination of glucose and lactate}

Serum was immediately prepared from blood samples taken with heparinised syringes and stored at $-80^{\circ} \mathrm{C}$ until analyses. Glucose was analysed according to the glucose oxidase method by mixing the samples with sodium acetate buffer ( $2 \mathrm{M}, \mathrm{pH} 5.5$ ) containing $0.1 \mathrm{mg} \mathrm{ml}^{-1}$ $o$-dianisidin, $4 \mathrm{U} \mathrm{ml}^{-1}$ glucose oxidase and 2.54 purpurgallin units of peroxidase (from horseradish) per $\mathrm{ml}$ on microtitre plates (Rotilabo ${ }^{\circ}$, Carl Roth AG, Karlsruhe, Germany). Plates were incubated at $37^{\circ} \mathrm{C}$ for $30 \mathrm{~min}$ and the reaction was stopped by addition of $100 \mu \mathrm{l} 12 \mathrm{~N}$ sulphuric acid to each well. Optical densities were read at $540 \mathrm{~nm}$ (Infinite M200, Tecan Group Ltd., Männedorf, Switzerland).

Lactate in serum and tissue samples was determined according to Maughan (1982)using hydrazine buffer $(1.1 \mathrm{mM}, \mathrm{pH}=9.0)$ and $227 \mu \mathrm{M}$ NAD, and $125 \mathrm{U} \mathrm{LDH}$ from porcine heart per well. After incubation for $30 \mathrm{~min}$ at room temperature optical densities were measured at $339 \mathrm{~nm}$ and lactate concentrations were calculated from a standard curve prepared with serial dilutions from a lactate standard (998 \pm $\left.6 \mathrm{mg} \mathrm{l}^{-1}\right)$.

\subsection{Measurement of total protein in serum}

Total protein content was analysed from diluted serum samples using the bicinchoninic acid (BCA) assay (Sigma) according to the manufacturer's protocol. After incubation for $60 \mathrm{~min}$ at room temperature, optical densities were measured at $536 \mathrm{~nm}$ (Infinite M200, Tecan Group Ltd., Männedorf, Switzerland).

\subsection{Measurement of AST, ALT, and SDH activity}

Activities of aspartate aminotransferase (AST) and alanine aminotransferase (ALT) from samples of $20 \mu \mathrm{l}$ serum or tissue homogenate were determined according to modified methods described by Casillas et al. (1982) after incubation for $30 \mathrm{~min}$ at room temperature by monitoring NADH oxidation at $339 \mathrm{~nm}$ (Infinite M200, Tecan Group Ltd., Männedorf, Switzerland). Sorbitol dehydrogenase (SDH) activity, that is responsible for the reversible conversion of fructose to sorbitol and vice versa, was measured in serum samples as described by Bergmeyer (1974b) using fructose as substrate. Absorption changes at a wavelength of $339 \mathrm{~nm}$ were recorded for 10 min (Infinite M200, Tecan Group Ltd., Männedorf, Switzerland).

\subsection{Estimation of metabolic rates by respirometry}

Fish were fasted for $24 \mathrm{~h}$ prior to the measurements to evacuate the digestive tract (Johansen and Jones, 2011; Shultz et al., 2011) and standardize a post-absorptive state that maximizes energy availability for swimming (Niimi and Beamish, 1974). Prior to the determination of metabolic rates individual body masses $(m$ ) were measured directly 
on a balance. Seven fish per treatment group $(m=35.4 \pm 1.5 \mathrm{~g}$; means \pm SEM) were selected randomly for measurement of oxygen consumption in the four-channel respirometer. The resting respirometry system (DAQ-PAC-F4X, Loligo Systems, Copenhagen, Denmark) that was used consisted of four cylindrical chambers (volume $5 \mathrm{~L}$, ID $100 \mathrm{~mm} \times$ length $250 \mathrm{~mm}$ ), fitted with fibre optic oxygen probes and immersed in a darkened, temperature-controlled plastic tank $(950 \times 810 \times 200 \mathrm{~mm}$, length $\times$ width $\times$ height) filled with aerated freshwater. The water temperature was maintained at $25.6 \pm 0.1^{\circ} \mathrm{C}$ (mean \pm actual range).

For each measurement three individuals were assigned to chambers in a random order. The fourth chamber, without fish stocking, was used to assess changes in oxygen levels originating from bacterial load. These background rates of respiration were significantly lower than in the chambers containing fish and accounted for $<10 \%$ of the oxygen consumption compared with the chambers containing fish which is also lower than reported for other respirometer measurements (Roche et al., 2013). In the present study, $\mathrm{MO}_{2}$ was measured using intermittent-flow respirometry (Steffensen et al., 1984; Steffensen, 1989). Individual chambers were connected to flush pumps (Eheim, $5 \mathrm{~L} / \mathrm{min}$ ) that turned on intermittently after each $\mathrm{MO}_{2}$ determination to replenish the chamber with oxygenated freshwater. A closed-loop recirculation pump also mixed the water inside the chamber during $\mathrm{MO}_{2}$ determinations. Oxygen levels in the respirometer were recorded using a Fibox 3 fiber optic oxygen meter (PreSens, Regensburg, Germany) using the AutoResp 1 respirometry software (AutoResp, Loligo Systems, Danmark). Periods of $13.5 \mathrm{~min}$ were used for the determinations with a $180 \mathrm{~s}$ flush, $30 \mathrm{~s}$ wait and $600 \mathrm{~s}$ measurement cycle. Once an individual's length and mass were input into the software, the fish was placed in the respirometer and left to habituate to the chamber for at least $30 \mathrm{~min}$ in the flush modus until oxygen consumption rates stabilized (Johansen et al., 2010; Binning et al., 2013). Thereafter, three determinations were run without using the data for later calculations to allow fish to adapt to the measurement procedures in the test chamber. Previous resting respirometry studies have averaged either three (Cutts et al., 2001; Brick and Cech, 2002; Cutts et al., 2002, Roche et al., 2013) or six $\mathrm{MO}_{2}$ measurements to obtain estimates for swimming metabolic rates (Schurmann and Steffensen, 1997; Gingerich et al., 2010; Norin and Malte, 2011; Shultz et al., 2011). For the present study, ten measurements for consistency with $\mathrm{MO}_{2}$ calculations were averaged for each set of fish, and $\mathrm{MO}_{2}\left(\mathrm{mg} \mathrm{O}_{2} \mathrm{~h}^{-1} \mathrm{~kg}^{-1}\right)$ were calculated for seven individual fish per treatment group.

\subsection{Statistics}

Effects of treatments were determined by comparison of treatment groups by using Kruskal Wallis tests followed by Mann-Whitney $U$ test (SPSS 9.0 for Windows). Relationships between parameters were evaluated using Spearman correlation tests. Differences between treatment groups were considered statistically significant when $P<0.05$.

\section{Results}

LDH activity was investigated in different organs (Table 1) showing lower activity in trunk kidney in fish treated with the medium than in fish treated with the low ZEN dose. In gill tissue, there was a higher LDH activity in fish treated with the high ZEN dose compared with fish fed the medium ZEN feed. In addition, muscle samples of fish fed the low ZEN diet showed a higher LDH activity than control fish. However, no differences in LDH activities could be observed in the other organs or any of the organs after two weeks of recovery, although the activities of LDH in liver after the first sampling and after the recovery phase showed a strong correlation (Spearman correlation coefficient, 0.730 , and significance, $p<0.000$ ), whereas the LDH activity in spleen showed an inverse correlation between these time points (Spearman correlation coefficient, -0.427 , and significance, $p=0.037$ ).
Table 1

Lactate dedydrogenase ( $\mathrm{LDH}, \mathrm{mU}$ mg protein ${ }^{-1}$ ) activity in tissue homogenates after ZEN feeding and 2 weeks recovery phase; $n=6$, means with the same letter are not significantly different from each other (significance tested with Mann-Whitney U-tests, $P<$ 0.05).

\begin{tabular}{lllll}
\hline & control & $\begin{array}{l}332 \mu \mathrm{kg}^{-1} \\
\text { ZEN }\end{array}$ & $\begin{array}{l}621 \mu \mathrm{kg}^{-1} \\
\text { ZEN }\end{array}$ & $\begin{array}{l}797 \mu \mathrm{kg}^{-1} \\
\text { ZEN }\end{array}$ \\
\hline $\begin{array}{lllll}\text { ZEN-treated: } \\
\text { head kidney }\end{array}$ & $101.0 \pm 20.4$ & $125.9 \pm 21.8$ & $94.1 \pm 18.7$ & $119.1 \pm 17.2$ \\
trunk kidney & $104.8 \pm 7.8^{\mathrm{a}, \mathrm{b}}$ & $123.5 \pm 6.9^{\mathrm{a}}$ & $100.7 \pm 5.4^{\mathrm{b}}$ & $110.5 \pm 11.6^{\mathrm{a}, \mathrm{b}}$ \\
spleen & $253.6 \pm 12.9$ & $272.6 \pm 17.6$ & $257.0 \pm 16.5$ & $231.4 \pm 31.1$ \\
liver & $221.0 \pm 71.9$ & $170.5 \pm 46.0$ & $249.5 \pm 79.9$ & $244.4 \pm 83.3$ \\
intestine & $291.4 \pm 56.7$ & $233.3 \pm 60.0$ & $348.6 \pm 43.8$ & $255.2 \pm 80.0$ \\
gill & $615.9 \pm 48.5^{\mathrm{a}, \mathrm{b}}$ & $555.3 \pm 20.3^{\mathrm{a}, \mathrm{b}}$ & $636.7 \pm 41.6^{\mathrm{a}}$ & $511.5 \pm 28.5^{\mathrm{b}}$ \\
muscle & $598.9 \pm 97.8^{\mathrm{a}}$ & $849.8 \pm 98.0^{\mathrm{b}}$ & $783.2 \pm 81.6^{\mathrm{a}, \mathrm{b}}$ & $802.2 \pm 50.2^{\mathrm{a}, \mathrm{b}}$ \\
& & & & \\
Recovery: & & & & \\
head kidney & $68.8 \pm 11.7$ & $86.5 \pm 28.9$ & $74.4 \pm 7.1$ & $92.2 \pm 16.3$ \\
trunk kidney & $52.9 \pm 10.5$ & $57.2 \pm 24.4$ & $42.2 \pm 12.5$ & $59.1 \pm 15.3$ \\
spleen & $326.8 \pm 27.4$ & $306.2 \pm 28.4$ & $356.2 \pm 21.8$ & $302.0 \pm 49.3$ \\
liver & $223.8 \pm 83.8$ & $308.3 \pm 95.2$ & $231.0 \pm 105.7$ & $210.8 \pm 80.0$ \\
intestine & $194.6 \pm 46.7$ & $212.0 \pm 61.5$ & $153.2 \pm 41.5$ & $281.9 \pm 109.4$ \\
gill & $324.0 \pm 59.5$ & $415.6 \pm 58.8$ & $247.9 \pm 31.8$ & $257.6 \pm 26.1$ \\
muscle & $664.4 \pm 83.8$ & $617.0 \pm 76.9$ & $631.1 \pm 85.7$ & $771.0 \pm 54.6$ \\
\hline
\end{tabular}

The activities of SDH, ALT and AST in liver are shown in Table 2. After four weeks of ZEN feeding no differences of these enzyme activities have been noted, but after two additional weeks of feeding the uncontaminated diet, SDH activities in fish fed the high ZEN dose showed higher activity levels compared with the control fish. At this time point, also a positive correlation between the ZEN concentrations during the previous feeding period and SDH activities in liver after recovery have been observed (Spearman correlation coefficient, 0.490 , and significance, $p=0.015$ ). Moreover, SDH activity in liver (Table 2 ) is also significantly correlated with SDH activity in serum (Table 3) after four weeks of experimental feeding (Spearman correlation coefficient, -0.461 , and significance, $p=0.031$ ).

Moreover, after the recovery phase the AST activity was lower in liver of fish previously fed the medium ZEN dose compared to those fed with the high ZEN diet, whereas the ALT activity in liver tissue was not influenced by ZEN feeding.

Several biochemical parameters in serum samples were influenced by ZEN feeding (Table 3). This included LDH activity in serum after four weeks of feeding which was lower in fish fed the highly contaminated ZEN diet compared with fish belonging to the other feeding groups. This difference was also present after two more weeks of feeding of the uncontaminated diet compared to all treatment groups. However, only after the four weeks of ZEN feeding, there was a positive correlation of ZEN concentrations with the LDH activity in serum (Spearman correlation coefficient, 0.454 , and significance, $p=0.034$ ). Four weeks of feeding ZEN also led to a difference in total serum protein levels between fish fed the medium ZEN dose and the high ZEN dose. Moreover, after the recovery phase, the serum lactate levels in fish treated previously with the highly ZEN-contaminated diet were found to be higher than in the remaining treatment groups. In addition, ALT activity in serum of fish treated with the low and medium ZEN dose was lower than in the control group and after the recovery phase of two weeks.

In liver tissue, lipid peroxidation was decreased by feeding the highest ZEN concentration whereas no difference was found in this organ after two weeks of recovery (Fig. 1A). Similarly, gills showed reduced lipid peroxidation, but only after exposure to the low dose ZEN diet, and to the high dose ZEN diet after the recovery phase (Fig. 2B). In addition, head kidney samples indicated reduced lipid peroxidation in fish that had been exposed to the low dose ZEN diet with additional two weeks of recovery (Fig. 3A). Organ damage as indicated by increased lipid peroxidation also occurred in spleen of fish fed the low dose ZEN diet for four weeks, and in the groups exposed to the medium 
Table 2

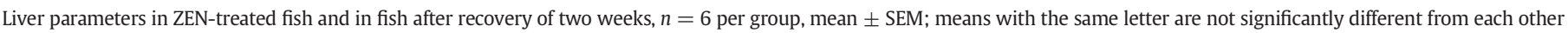
(significance tested with Mann-Whitney U-tests, $P<0.05$ ), SDH $=$ sorbitol dehydrogenase, AST $=$ aspartate aminotransferase, ALT $=$ alanine aminotransferase.

\begin{tabular}{|c|c|c|c|c|}
\hline & control & $332 \mu \mathrm{g} \mathrm{kg}^{-1} \mathrm{ZEN}$ & $621 \mu \mathrm{g} \mathrm{kg}^{-1} \mathrm{ZEN}$ & $797 \mu \mathrm{g} \mathrm{kg}^{-1} \mathrm{ZEN}$ \\
\hline \multicolumn{5}{|l|}{ ZEN-treated: } \\
\hline $\mathrm{SDH}\left[\mathrm{mU}\right.$ mg protein $\left.{ }^{-1}\right]$ & $4.3 \pm 1.5$ & $2.9 \pm 0.8$ & $2.6 \pm 0.6$ & $3.1 \pm 0.9$ \\
\hline AST [U mg protein ${ }^{-1}$ ] & $1.6 \pm 0.9$ & $0.8 \pm 0.4$ & $1.3 \pm 0.4$ & $0.6 \pm 0.1$ \\
\hline ALT [mU mg protein $\left.{ }^{-1}\right]$ & $87.7 \pm 27.8$ & $130.7 \pm 23.9$ & $152.5 \pm 20.3$ & $110.0 \pm 20.7$ \\
\hline \multicolumn{5}{|l|}{ Recovery: } \\
\hline $\mathrm{SDH}\left[\mathrm{mU}\right.$ mg protein $\left.{ }^{-1}\right]$ & $2.6 \pm 0.4^{\mathrm{a}}$ & $4.4 \pm 1.1^{\mathrm{a}, \mathrm{b}}$ & $3.5 \pm 0.5^{\mathrm{a}, \mathrm{b}}$ & $4.4 \pm 0.3^{b}$ \\
\hline AST [U mg protein ${ }^{-1}$ ] & $1.5 \pm 0.8^{\mathrm{a}, \mathrm{b}}$ & $1.0 \pm 0.2^{\mathrm{a}, \mathrm{b}}$ & $0.3 \pm 0.0^{\mathrm{a}}$ & $1.1 \pm 0.2^{\mathrm{b}}$ \\
\hline ALT [mU mg protein $\left.{ }^{-1}\right]$ & $24.4 \pm 9.8$ & $32.4 \pm 7.6$ & $19.6 \pm 4.7$ & $39.4 \pm 9.1$ \\
\hline
\end{tabular}

and higher ZEN concentration after the recovery phase (Fig. 3C). Moreover, no differences in lipid peroxidation after ZEN feeding were observed in intestine (Fig. 1B), white muscle tissue (Fig. 2A) and samples from trunk kidneys (Fig. 3B).

Finally, significant differences in the respiratory oxygen demand of fish treated with the medium and high ZEN-contaminated diet compared with the control diet were observed (Fig. 4) whereas the difference to the low ZEN diet was not significant $(P=0.073)$ compared with the control fish. Nevertheless, a correlation of ZEN concentrations with the respiratory oxygen demand of the experimental fish has been noted (Spearman correlation coefficient, 0.399, and significance, $p=0.035$ ). In addition, the respiratory oxygen demand of the carp showed also a relationship with the LPO level in liver after ZEN feeding and after the recovery phase (Spearman correlation coefficients, 0.453 and 0.449 , and significance, $p=0.026$ and $p=0.028$, respectively). Moreover, the results of the respirometric measurements also correlated well with the SDH activity in liver and the ALT activity in serum after the recovery phase (Spearman correlation coefficients, 0.616 and 0.001 , and significance, $p=0.026$ and $p=0.045$, respectively).

\section{Discussion}

Toxicity of ZEN has been identified in different organs of vertebrates including fish. In fish, hepatotoxic, immunotoxic and genotoxic effects, effects on reproduction and changes of blood parameters have been described so far (Pietsch et al., 2015a, 2015b; Johns et al., 2009; Schwartz et al., 2010; Woźny et al., 2012; Bakos et al., 2013; Woźny et al., 2015). Toxicity of ZEN has thereby mostly been assumed to be due to its possible endocrine and developmental impairment since it is a potent phytoestrogen (Bakos et al., 2013; Woźny et al., 2015), but several effects of ZEN on fish cells have also been related to oxidative stress (Pietsch et al., 2014a). In other vertebrates also cytopathic and calcium-triggered apoptotic modes of action after ZEN treatment have been described (Vlata et al., 2006; Jilani and Lang, 2013).

The present study provides more evidence of organ-wide effects of ZEN in carp and reports a large variety of biochemical serum parameters which are known to be affected by many endogenous and exogenous factors including age, health condition, nutrition or stress, including chemical stress (Svobodova et al., 2006; Hoseini and Ghelichpour, 2013). Total protein content in serum of all carp used in the present study was slightly lower in most cases (Table 3 ) compared with previously reported values in other studies (Hoseini and Ghelichpour, 2013; Varga et al., 2013; Pietsch et al., 2014b). Serum total protein levels are known to reflect nutritional condition of carp and it may still be assumed that in general the nutritional status of the fish was sufficient in the present study (Navarro and Gutiérrez, 1995). No evidence for an influence of ZEN feeding on blood glucose could be observed, although possible variations of blood glucose might also have been compensated in ZEN-treated fish. Similar to other fishes, carp are known to maintain blood glucose levels even after prolonged starvation (Navarro and Gutiérrez, 1995). Serum lactate levels in all fish are comparable to values in unstressed fish in other studies (Pottinger, 1998; Hoseini and Ghelichpour, 2013), and lactate values in ZEN-treated carp after four weeks of treatment were not different compared to the control fish. However, a higher serum lactate value was observed in ZENtreated fish after the recovery phase. This may be caused by reduced LDH activity possibly in combination with an activation of gluconeogenesis to maintain or increase levels of circulating glucose in carp (Hoseini and Ghelichpour, 2013). In addition, lactic acid in the blood circulation can increased in order to replenish glycogen in recovering muscle via gluconeogenesis as has been observed in anaerobic swimming muscle of the teleost fish Pleuronectes platessa L. after exhausting exercise (Batty and Wardle, 1979). Thus, it can be assumed that ZEN affects anaerobic metabolism in carp. In parallel, LDH activities were decreased

Table 3

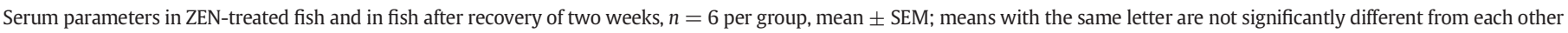

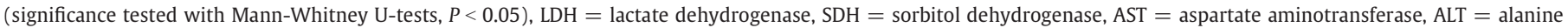
aminotransferase.

\begin{tabular}{|c|c|c|c|c|}
\hline & control & $332 \mu \mathrm{g} \mathrm{kg}^{-1} \mathrm{ZEN}$ & $621 \mu \mathrm{g} \mathrm{kg}^{-1} \mathrm{ZEN}$ & $797 \mu \mathrm{g} \mathrm{kg}^{-1} \mathrm{ZEN}$ \\
\hline \multicolumn{5}{|l|}{ ZEN-treated: } \\
\hline Free glucose $\left[\mu \mathrm{M} \mathrm{ml}^{-1}\right]$ & $3.1 \pm 0.3$ & $2.8 \pm 0.2$ & $3.0 \pm 0.2$ & $3.9 \pm 0.6$ \\
\hline Lactate $\left[\mu \mathrm{M} \mathrm{ml}^{-1}\right]$ & $2.4 \pm 0.3$ & $3.2 \pm 0.8$ & $3.5 \pm 1.0$ & $3.0 \pm 0.7$ \\
\hline $\mathrm{LDH}\left[\mathrm{mU}\right.$ mg protein $\left.{ }^{-1}\right]$ & $22.4 \pm 3.0^{\mathrm{a}}$ & $17.5 \pm 3.8^{a}$ & $17.3 \pm 4.4^{\mathrm{a}}$ & $11.6 \pm 2.7^{\mathrm{b}}$ \\
\hline $\mathrm{SDH}\left[\mathrm{mU}\right.$ mg protein $\left.{ }^{-1}\right]$ & $7.7 \pm 2.7$ & $6.8 \pm 2.2$ & $10.7 \pm 1.6$ & $7.0 \pm 1.7$ \\
\hline AST [U mg protein $\left.{ }^{-1}\right]$ & $1.2 \pm 0.4$ & $1.1 \pm 0.3$ & $0.8 \pm 0.2$ & $0.7 \pm 0.2$ \\
\hline ALT [mU mg protein $\left.{ }^{-1}\right]$ & $95.4 \pm 22.7$ & $113.3 \pm 32.6$ & $79.4 \pm 21.9$ & $72.3 \pm 29.6$ \\
\hline Total protein $\left[\mathrm{mg} \mathrm{ml}^{-1}\right]$ & $17.6 \pm 1.2^{\mathrm{a}, \mathrm{b}}$ & $18.2 \pm 1.4^{\mathrm{a}, \mathrm{b}}$ & $15.9 \pm 0.5^{\mathrm{a}}$ & $19.2 \pm 1.0^{\mathrm{b}}$ \\
\hline \multicolumn{5}{|l|}{ Recovery: } \\
\hline Free glucose $\left[\mu \mathrm{M} \mathrm{ml}^{-1}\right]$ & $1.5 \pm 0.4$ & $1.9 \pm 0.4$ & $2.2 \pm 0.1$ & $1.9 \pm 0.3$ \\
\hline Lactate $\left[\mu \mathrm{M} \mathrm{ml}^{-1}\right]$ & $1.8 \pm 0.1^{\mathrm{a}}$ & $2.0 \pm 0.5^{\mathrm{a}}$ & $2.3 \pm 0.3^{\mathrm{a}}$ & $5.8 \pm 0.7^{\mathrm{b}}$ \\
\hline $\mathrm{LDH}\left[\mathrm{mU}\right.$ mg protein $\left.{ }^{-1}\right]$ & $27.0 \pm 4.5^{\mathrm{a}}$ & $21.6 \pm 3.6^{\mathrm{a}}$ & $29.9 \pm 2.2^{\mathrm{a}}$ & $13.3 \pm 3.3^{b}$ \\
\hline $\mathrm{SDH}\left[\mathrm{mU}\right.$ mg protein $\left.{ }^{-1}\right]$ & $7.0 \pm 1.8$ & $7.2 \pm 1.8$ & $9.8 \pm 2.2$ & $11.0 \pm 1.1$ \\
\hline AST [U mg protein $\left.{ }^{-1}\right]$ & $0.6 \pm 0.1$ & $0.8 \pm 0.3$ & $1.0 \pm 0.6$ & $0.7 \pm 0.2$ \\
\hline ALT [mU mg protein $\left.{ }^{-1}\right]$ & $109.4 \pm 19.9^{\mathrm{a}}$ & $22.5 \pm 4.7^{\mathrm{b}}$ & $33.5 \pm 7.4^{b}$ & $61.0 \pm 33.6^{\mathrm{a}, \mathrm{b}}$ \\
\hline Total protein $\left[\mathrm{mg} \mathrm{ml}^{-1}\right]$ & $17.8 \pm 1.3$ & $17.9 \pm 1.3$ & $15.3 \pm 0.6$ & $16.7 \pm 1.0$ \\
\hline
\end{tabular}



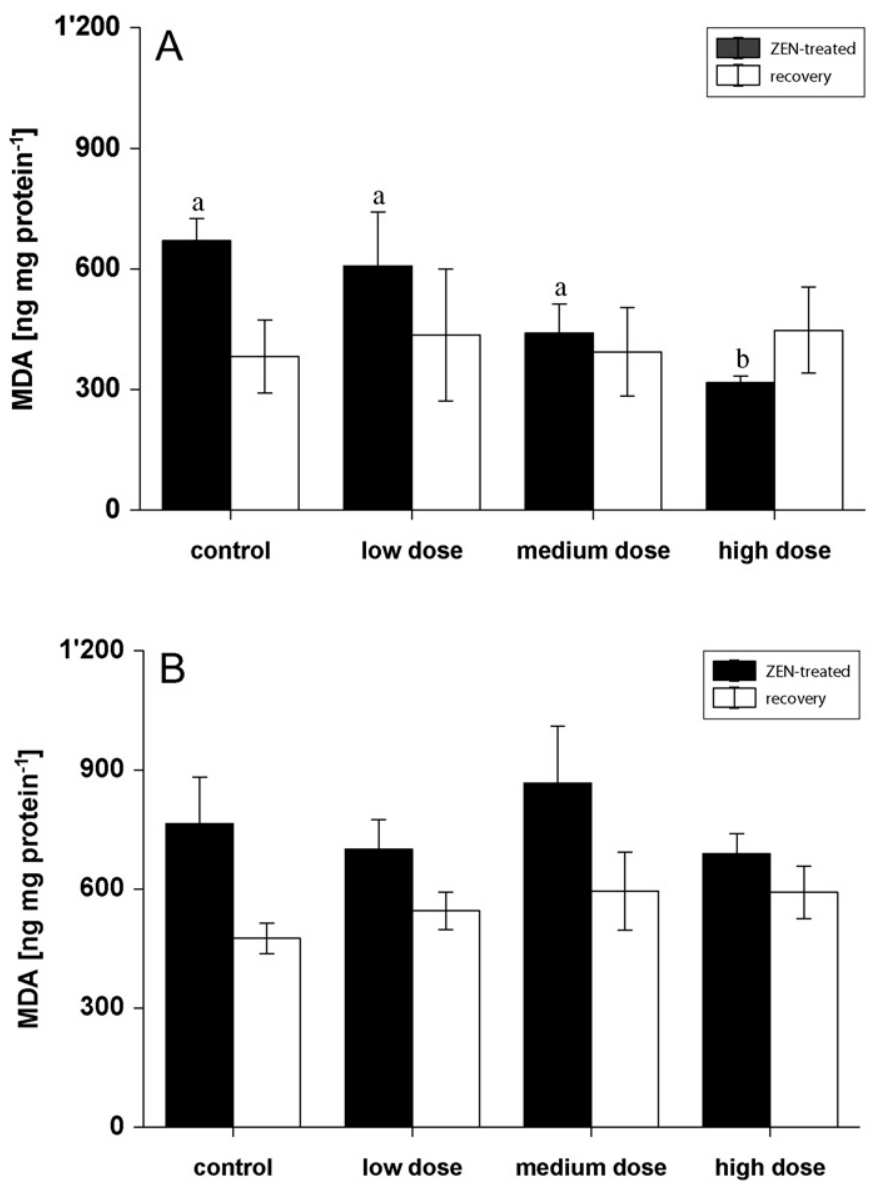

Fig. 1. Lipid peroxidation measured as malondialdehyde (MDA; ng mg protein ${ }^{-1}$ ) in different tissues [(A) liver, (B) intestine] in experimental fish with four weeks of ZEN feeding (ZEN-treated) and ZEN-fed fish with an additional two weeks of recovery (recovery); mean \pm SEM; means with the same letter ( $a$ and/or b) are not significantly different from each other (significance tested with Mann-Whitney U-tests, $p<0.05$ ).

in serum of carp fed the highest ZEN dose compared with the control fish which was also observed after feeding similarly treated fish for two more weeks with the uncontaminated diet. Since increased LDH activity in blood circulation would be related to organ damages indicating membrane leakage in tissues as has been shown after exposure of carp to toxic concentrations of pesticides and the mycotoxin deoxynivalenol (Asztalos and Nemcsok, 1985; Pietsch et al., 2014b), these are not indicated in serum samples of ZEN-treated carp. Despite effects on LDH activities, significant increases of AST and ALT have been observed in carp that have been exposed to handling stress, regular exercise or toxic substances such as deoxynivalenol, microcystins and cyanide (Carbis et al., 1997; Li et al., 2004; Dobšíková et al., 2009; Sadati et al., 2013; Varga et al., 2013; Pietsch et al., 2014b). Compared to this, ZEN-treated carp only showed minor effects on AST and ALT activities after four weeks as well as after two more weeks of feeding the uncontaminated diet.

SDH activity, which is primarily found in liver, has also been investigated in the present study, since it has been shown to be a precise, but not disease-specific measure of sublethal liver damage in mammalian species (Wiesner et al., 1965; Travlos et al., 1996). In the present study, increased SDH activity was observed in liver of carp fed the high ZEN dose followed by additional feeding for two weeks with the uncontaminated diet. Increased SDH activity in liver has also been observed after exposure of fish to toxic substances (Sastry and Siddiqui, 1982; Dixon et al., 1987). Moreover, SDH in liver inversely correlated with SDH activity in serum after four weeks of experimental feeding. Compared to the present study, SDH activity in serum of carp was slightly higher in another feeding study using carp which showed reduced

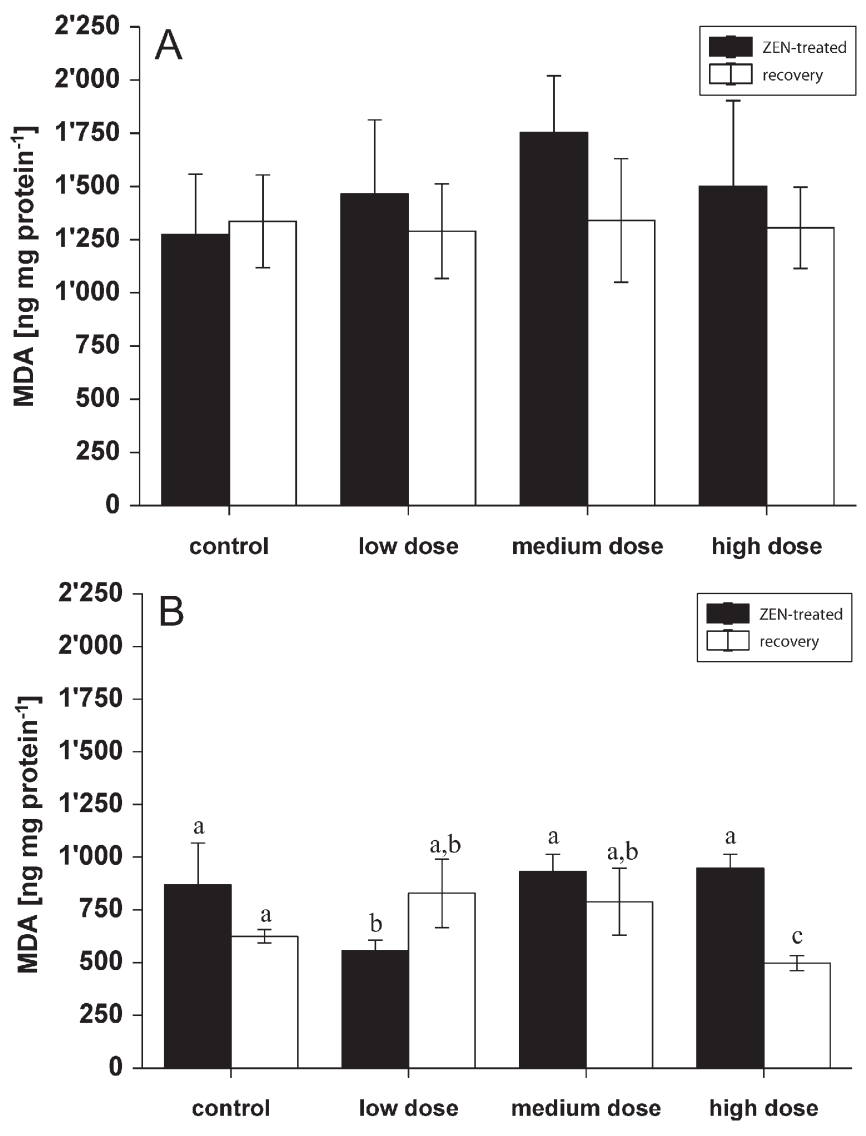

Fig. 2. Lipid peroxidation measured as malondialdehyde (MDA; ng mg protein ${ }^{-1}$ ) in different tissues [(A) white muscle, (B) gill] in experimental fish with four weeks of ZEN feeding (ZEN-treated) and ZEN-fed fish with an additional two weeks of recovery (recovery); mean \pm SEM; means with the same letter (a and/or b) are not significantly different from each other (significance tested with Mann-Whitney U-tests, $p<0.05$ ).

SDH activity after being fed a diet contaminated with $953 \mu \mathrm{g}$ of the mycotoxin deoxynivalenol per kg feed for four weeks (Pietsch et al., 2014b). Consequently, the symptoms of carp exposed to ZEN partly resemble the situation of fish after exposure to sublethal concentrations of carbamate pesticide or the mycotoxin deoxynivalenol since these showed increases of LDH and decreased SDH activity in several organs often accompanied by hyperglycaemia and hyperlactaemia, which suggested that anaerobic metabolism was favored (Sastry and Siddiqui, 1982; Pietsch et al., 2014b).

In parallel, lipid peroxidation was low in liver, head kidney and gills of ZEN-treated fish. This was probably due to cellular mechanisms that counteract or even over-compensated the effects of ZEN on these organs. Only in spleen, increased lipid peroxidation occurred in fish fed the low dose ZEN diet and in both groups exposed to the higher ZEN concentration after the recovery phase. Increased lipid peroxidation is often caused by oxidative stress which has already been shown to be involved in ZEN toxicity in fish cells (Pietsch et al., 2014a). In addition these results show that, recovery of two weeks did not improve the organ status in all cases. Moreover, intestine, white muscle tissue, and samples from trunk kidneys showed no differences in lipid peroxidation after ZEN feeding.

In summary, the conducted experiments proved that ZEN exposure of carp affects several organs in this fish species and leads to metabolic alterations. Since the contamination of experimental diets containing the low dose was comparable to ZEN values in commercially available feeding stuffs (Pietsch et al., 2013) and all concentrations were lower than the current guidance value by the European Commission of $2 \mathrm{mg} \mathrm{kg}^{-1}$ feed (European Commission, 2006), the used range of ZEN is highly relevant for fish in aquaculture. This will be even more 

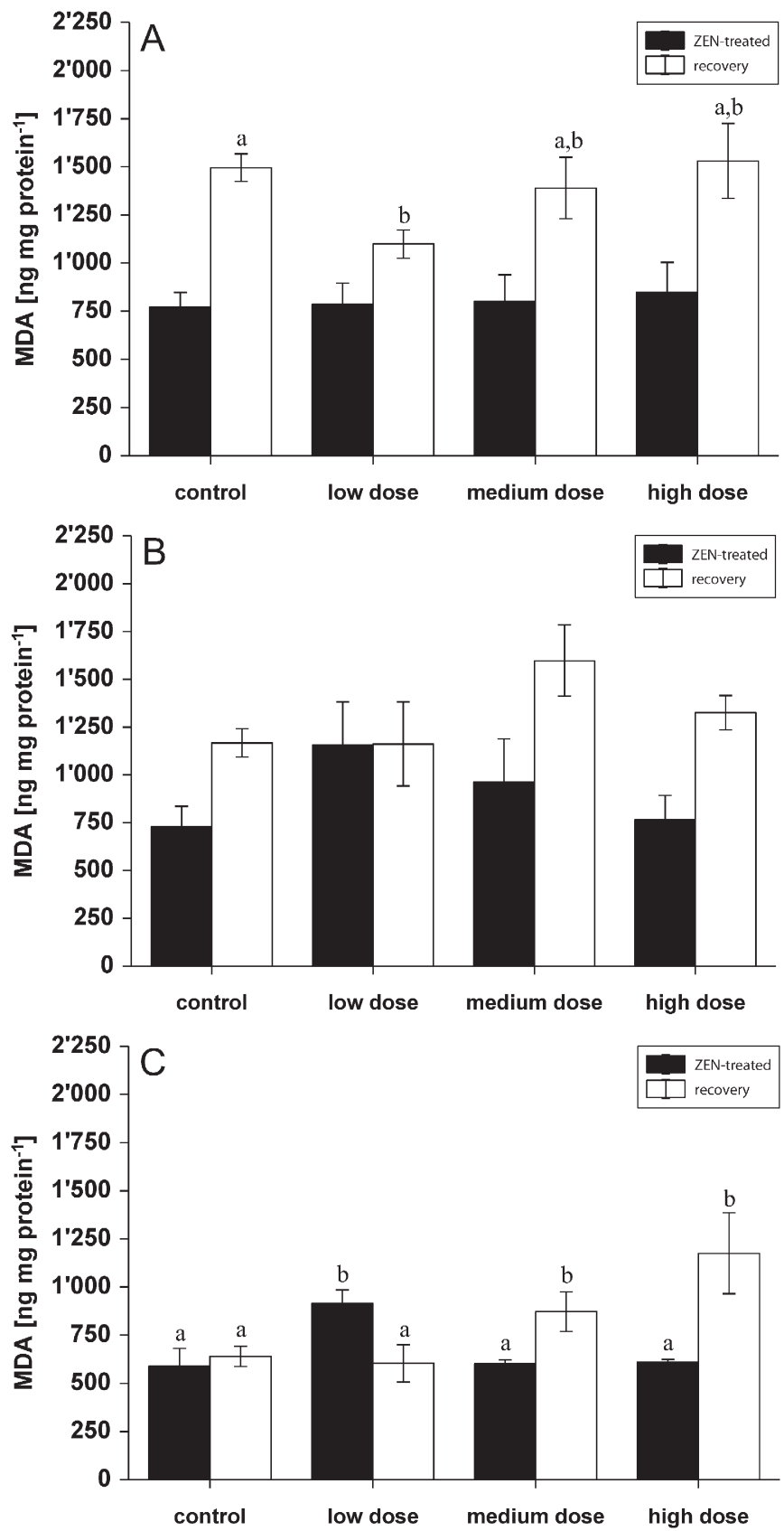

Fig. 3. Lipid peroxidation measured as malondialdehyde (MDA; ng mg protein ${ }^{-1}$ ) in different tissues [(A) head kidney, (B) trunk kidney, (C) spleen] in experimental fish with four weeks of ZEN feeding (ZEN-treated) and ZEN-fed fish with an additional two weeks of recovery (recovery); mean \pm SEM; means with the same letter (a and/or b) are not significantly different from each other (significance tested with MannWhitney U-tests, $p<0.05$ ).

important when metabolic rates in fish are concerned. It has already been shown that irrespective of the chemical mode of action, foreign substances are able to influence metabolic rates (MacLeod and Pessah, 1973; Beyers et al., 1999), and the present study indicates that the same is true for ZEN exposure of carp. However, it is also known that temperature, mass and activity affect fish respirometry measurements (Schurmann and Steffensen, 1997; Johansen and Jones, 2011; Shultz et al., 2011; Roche et al., 2013). Body masses of fish were not significantly different between the treatment groups (Pietsch et al., 2015a) and temperature was kept constant during the experiments. Differences of motoric activity have not been obvious from the present study. Temperatures have been kept constant during the entire experiments. Thus, it is

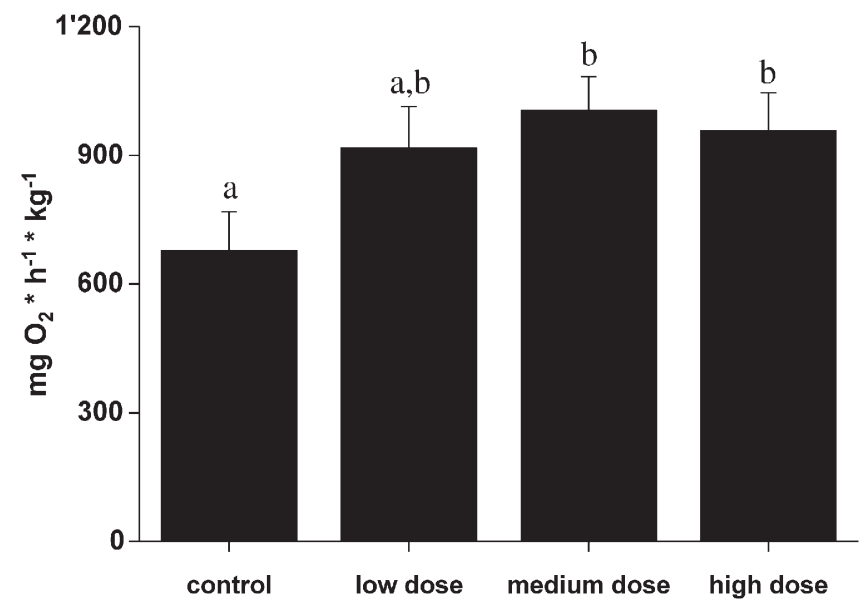

Fig. 4. Oxygen consumption (calculated per mg oxygen per hour per kg fish) of carp after 4 weeks of feeding ZEN measured by intermittent respirometry, $n=7$; mean $\pm \mathrm{SEM} ;{ }^{*}=$ difference to controls at $P<0.05$.

concluded that ZEN was responsible for the differences in oxygen consumption in ZEN-treated carp. Fish that are exposed to chemical stressors are known to activate physiological mechanisms in order to maintain homeostasis (Barton, 2002). If the effects of chemical exposure cannot be compensated for, then damage occurs and repair mechanisms must be activated. While it is difficult to identify individual processes that take part in these mechanisms, metabolic rate is a good measure of the energy being expended for compensation because it integrates all physiological processes. Since the exact cellular targets of ZEN in fish and the resulting impact on their well-being have not yet been completely revealed, the measurement of metabolic rates is important to show organism-wide consequences of the exposure to this mycotoxin.

The present study shows that routine metabolic rate is influenced by ZEN exposure which is consistent with the general concept of adaptation. During the first stage of adaptation, the amount of energy for compensating for stressor effects declines because toxic effects combined with the side effects, such as lethargy and loss of appetite, and then increases until homeostasis is achieved. However, growth performance of carp is not influenced by ZEN feeding and effects of ZEN on the fish's appetite have not been observed during the entire duration of the experiments (Pietsch et al., 2015a). The present results, therefore, suggest that after four weeks of exposure to ZEN carp had progressed to the second stage of the general adaptation syndrome where compensations costs belong to the "normal" costs of living, which is reflected by a higher metabolic rate in exposed fish. This probably also has consequences for husbandry of fish in aquaculture, because further stressors may lead to cumulative effects of multiple stressors which can deplete an organism's reserves, thereby reducing its ability to cope.

\section{Conclusions}

ZEN influences anaerobic metabolism but also increases metabolic costs in carp as has been shown by respirometry. These effects occurred at dietary concentrations that are below the maximum allowable levels recommended by the European Commission (2006) which raises concern about impairment of fish health by improper feeding in aquaculture. Complete recovery from ZEN effects was not achieved after two weeks of feeding the uncontaminated diet which emphasizes the negative impact of this mycotoxin on carp. In addition, the environment of an organism plays an important role in its ability to compensate for effects of contaminant exposure and the consequences of cumulative effects of multiple stressors should be investigated more in detail in the future. 


\section{Conflict of interests}

The authors declare that there is no conflict of interest regarding the publication of this paper.

\section{Acknowledgements}

We are grateful to Carsten Schulz (Gesellschaft für Marine Aquakultur (GMA)mbH, Büsum, Germany) for the opportunity to prepare the experimental diets. Furthermore, the analyses of mycotoxin concentrations in the feeds by Susanne Kersten, Hana Valenta, and Sven Dänicke (Friedrich-Loeffler-Institute (FLI), Braunschweig, Germany) are greatly acknowledged. The authors also like to thank Patricia Burkhardt-Holm and her research group "Man - Society - Environment" for giving us the opportunity to conduct the experiments at the University of Basel (Switzerland).

\section{References}

Asztalos, B., Nemcsok, J., 1985. Effect of pesticides on the LDH activity and isoenzyme pattern of carp (Cyprinus carpio L.) sera. Comp. Biochem. Physiol. 82C, 217-219.

Bakos, K., Kovács, R., Staszny, Á., Sipos, D.K., Urbányi, B., Müller, F., Csenki, Z., Kovács, B., 2013. Developmental toxicity and estrogenic potency of zearalenone in zebrafish (Danio rerio). Aquat. Toxicol. 136-137, 13-21.

Barton, B.A., 2002. Stress in fishes: A diversity of responses with particular reference to changes in circulating corticosteroids. Integr. Comp. Biol. 42, 517-525.

Batty, R.S., Wardle, C.S., 1979. Restoration of glycogen from lactic acid in the anaerobic swimming muscle of plaice, Pleuronectes platessa L. J. Fish Biol. 15, 509-519.

Bergmeyer, H.U., 1974a. Lactate dehydrogenase. Methods of Enzymatic Analysis, second ed. Academic Press, London, UK, pp. 574-579.

Bergmeyer, H.U., 1974b. In: Weinheim, V.C. (Ed.), Sorbitol dehydrogenase. In Methods of Enzymatic Analysis, third ed. Academic Press, London, UK, pp. 569-573.

Beyers, D.W., Rice, J.A., Clements, W.H., Henry, C.J., 1999. Estimating physiological cost of chemical exposure: integrating energetics and stress to quantify toxic effects in fish. Can. J. Fish. Aquat. Sci. 56, 814-822.

Binning, S.A., Roche, D.G., Layton, C., 2013. Ectoparasites increase swimming costs in a coral reef fish. Biol. Lett. 9, 20120927.

Brick, M.E., Cech, J.J., 2002. Metabolic responses of juvenile striped bass to exercise and handling stress with various recovery environments. Trans. Am. Fish. Soc. 131, 855-864.

Carbis, C.R., Rawlin, G.T., Grant, P., Mitchell, G.F., Anderson, J.W., McCauley, I., 1997. A study of feral carp, Cyprinus carpio L., exposed to Microcystis aeruginosa at Lake Mokoan, Australia, and possible implications for fish health. J. Fish Dis. 20, 81-91.

Casillas, E., Sundquist, J., Ames, W.E., 1982. Optimization of assay conditions for, and the selected tissue distribution of, alanine aminotransferase and aspartate aminotransferase of English sole Parophrys vetulus Girard. J. Fish Biol. 21, 197-204.

Cutts, C.J., Adams, C.E., Campbell, A., 2001. Stability of physiological and behavioural determinants of performance in Arctic charr (Salvelinus alpinus). Can. J. Fish. Aquat. Sci. 58, 961-968

Cutts, C.J., Metcalfe, N.B., Taylor, A.C., 2002. Juvenile Atlantic salmon (Salmo salar) with relatively high standard metabolic rates have small metabolic scopes. Funct. Ecol. $16,73-78$

Dixon, D.G., Hodson, P.V., Kaiser, K.L.E., 1987. Serum sorbitol dehydrogenase activity as an indicator of chemically induced liver damage in rainbow trout. Environ. Toxicol. Chem. 6, 685-696

Dobšíková, R., Svobodová, Z., Bláhová, J., Modrá, H., Velǐšek, J., 2009. The effect of transport on biochemical and haematological indices of common carp (Cyprinus carpio L.). Czech J. Anim. Sci. 54, 510-518.

Döll, S., Valenta, H., Baardsen, G., Möller, P., Koppe, W., Stubhaug, I., Dänicke, S., 2011. Effects of increasing concentrations of deoxynivalenol, zearalenone and ochratoxin $A$ in diets for Atlantic salmon (Salmo salar) on performance, health and toxin residues. Proceedings, 33rd Mycotoxin Workshop. Freising, Germany, p. 25 30.05.-01.06.2011.

European Commission, 2006. Commission Recommendation (2006/576/EC) of 17 August 2006 on the presence of deoxynivalenol, zearalenone, ochratoxin A, T-2 and HT-2 and fumonisins in products intended for animal feeding. Off. J. Eur. Union L229/7-L229/9.

Gingerich, A.J., Philipp, D.P., Suski, C.D., 2010. Effects of nutritional status on metabolic rate, exercise and recovery in a freshwater fish. J. Comp. Physiol. B. 180, 371-384.

Greco, M., Pardo, A., Pose, G., 2015. Mycotoxigenic fungi and natural co-occurrence of mycotoxins in rainbow trout (Oncorhynchus mykiss) feeds. Toxins 7, 4595-4609.

Holt, S., Gunderson, M., Joyce, K., Nayini, N.R., Eyster, G.F., Garitano, A.M., Zonia, C., Krause, G.S., Aust, S.D., White, B.C., 1986. Myocardial tissue iron delocalization and evidence for lipid peroxidation after two hours of ischemia. Ann. Emerg. Med. 15, 1155-1159.

Hoseini, S.M., Ghelichpour, M., 2013. Effects of pre-sampling fasting on serum characteristics of common carp (Cyprinus carpio L.). Int. J. Aquat. Biol. 1, 6-13.

Jilani, K., Lang, F., 2013. $\mathrm{Ca}^{2+}$-dependent suicidal erythrocyte death following zearalenone exposure. Arch. Toxicol. 87, 1821-1828.

Johansen, J.L., Jones, G.P., 2011. Increasing ocean temperature reduces the metabolic performance and swimming ability of coral reef damselfishes. Glob. Chang. Biol. 17 2971-2979.
Johansen, J.L., Vaknin, R., Steffensen, J.F., Domenici, P., 2010. Kinematics and energetic benefits of schooling in the labriform fish, striped surfperch Embiotoca lateralis. Mar. Ecol. Prog. Ser. 420, 221-229.

Johns, S.M., Denslow, N.D., Kane, M.D., Watanabe, K.H., Orlando, E.F., Sepulveda, M.S., 2009. Effects of estrogens and antiestrogens on gene expression of fathead minnow (Pimephales promelas) early life stages. Environ. Toxicol. 26 (2), 195-206.

Li, X.-Y., Chung, I.-K., Kim, J.-I., Lee, J.-A., 2004. Subchronic oral toxicity of microcystin in common carp (Cyprinus carpio L.) exposed to Microcystis under laboratory conditions. Toxicon 44, 821-827.

MacLeod, J.C., Pessah, E., 1973. Temperature effects on mercury accumulation, toxicity and metabolic rate in rainbow trout (Salmo gairdneri). J. Fish. Res. Board Can. 30, 485-492.

Maughan, R.J., 1982. A simple, rapid method for the determination of glucose, lactate, pyruvate, alanine, 3-hydroxybutyrate and acetoacetate on a single $20-\mu \mathrm{L}$ blood sample. Clin. Chim. Acta 122, 231-240.

Navarro, I., Gutiérrez, J., 1995. Chapter 17. Fasting and starvation. In: Hochachka, P.W. Mommsen, T.P. (Eds.), BiochemMolecular Biology of Fishes, Volume Vol. 4. Elsevier, Amsterdam, pp. 393-434.

Niimi, A.J., Beamish, F.W.H., 1974. Bioenergetics and growth of largemouth bass (Micropterus salmoides) in relation to body weight and temperature. Can. J. Zool. 52, 447-456.

Norin, T., Malte, H., 2011. Repeatability of standard metabolic rate, active metabolic rate and aerobic scope in young brown trout during a period of moderate food availability. J. Exp. Biol. 214, 1668-1675.

Pietsch, C., Kersten, S., Burkhardt-Holm, P., Valenta, H., Dänicke, S., 2013. Occurrence of deoxynivalenol and zearalenone in commercial fish feed. An initial study. Toxins 5 , 184-192.

Pietsch, C., Noser, J., Wettstein, F.E., Burkhardt-Holm, P., 2014a. Unravelling the mechanisms involved in zearalenone-mediated toxicity in permanent fish cell cultures. Toxicol. Sci. 88, 44-61.

Pietsch, C., Schulz, C., Robiero, P., Kloas, W., Burkhardt-Holm, P., 2014b. Organ damage and altered nutritional condition in carp (Cyprinus carpio L.) after food-borne exposure to the mycotoxin deoxynivalenol (DON). Toxins 6, 756-778.

Pietsch, C., Junge, R., Burkhardt-Holm, P., 2015b. Immunomodulation by zearalenone (ZEN) in carp (Cyprinus carpio L.). Bio Med Res. Int. 2015a. http://dx.doi.org/10 1155/2015/420702 Article ID 420702, (9 pages).

Pietsch, C., Kersten, S., Valenta, H., Dänicke, S., Burkhardt-Holm, P., Junge, R., 2015a. Effects of dietary exposure to zearalenone (ZEN) on carp (Cyprinus carpio L.). Toxins 7 (9), 3465-3480.

Pottinger, T.G., 1998. Changes in blood cortisol, glucose and lactate in carp retained in anglers` keepnets. J. Fish Biol. 53, 728-742.

Rau, M.A., Whitaker, J., Freedman, J.H., Di Giulio, R.T., 2004. Differential susceptibility of fish and rat liver cells to oxidative stress and cytotoxicity upon exposure to prooxidants. Comp. Biochem. Physiol. C 137, 335-342.

Roche, D.G., Binning, S.A., Bosiger, Y., Johansen, J.L., Rummer, J.L., 2013. Finding the bes estimates of metabolic rates in a coral reef fish. J. Exp. Biol. 216, 2103-2110.

Sadati, F., Shahsavani, D., Baghshani, H., 2013. Biochemical alterations induced by sublethal cyanide exposure in common carp (Cyprinus carpio). J. Biol. Environ. Sci. 7 (20), 65-69.

Santos, G.A., Rodrigues, I., Naehrer, K., Encarnacao, P., 2010. Mycotoxins in aquaculture: occurrence in feed components and impact on animal performance. Aquacult. Euro. $35,6-10$.

Sastry, K.V., Siddiqui, A.A., 1982. Chronic toxic effects of the carbamate pesticide sevin on carbohydrate metabolism in a freshwater snakehead fish, Channa punctatus. Toxicol. Lett. 14, 123-130.

Schulte, P.M., 2014. What is environmental stress? Insights from fish living in a variable environment. J. Exp. Biol. 217, 23-34. http://dx.doi.org/10.1242/jeb.089722.

Schurmann, H., Steffensen, J.F., 1997. Effects of temperature, hypoxia and activity on the metabolism of juvenile Atlantic cod. J. Fish Biol. 50, 1166-1180.

Schwartz, P., Thorpe, K.L., Bucheli, T.D., Wettstein, F.E., Burkhardt-Holm, P., 2010. Shortterm exposure to the environmentally relevant estrogenic mycotoxin zearalenone impairs reproduction in fish. Sci. Total Environ. 409, 326-333.

Shultz, A.D., Murchie, K.J., Griffith, C., Cooke, S.J., Danylchuk, A.J., Goldberg, T.L., Suski, C.D. 2011. Impacts of dissolved oxygen on the behavior and physiology of bonefish: implications for live-release angling tournaments. J. Exp. Mar. Biol. Ecol. 402, 19-26.

Steffensen, J.F., 1989. Some errors in respirometry of aquatic breathers: how to avoid and correct them. Fish Physiol. Biochem. 6, 49-59.

Steffensen, J.F., Johansen, K., Bushnell, P.G., 1984. An automated swimming respirometer Comp. Biochem. Physiol. 79A, 437-440.

Svobodova, Z., Vykusova, B., Modra, H., Jarkovsky, J., Smutna, M., 2006. Haematological and biochemical profile of harvest-size carp during harvest and post-harvest storage. Aquac. Res. 37, 959-965.

Travlos, G.S., Morris, R.W., Elwell, M.R., Duke, A., Rosenblum, S., Thompson, M.B., 1996 Frequency and relationship of clinical chemistry and liver and kidney histopathology findings in 13-week toxicity studies in rats. Toxicology 107, 17-29.

van Ginneken, V., van den Thillart, G., 2009. Metabolic depression in fish measured by direct calorimetry: A review. Thermochim. Acta 483, 1-7.

Varga, D., Molnár, T. Balogh, K., Mézes, M., Hancz, C., Szabó, A. 2013. Adaptation of Common Carp (Cyprinus carpio L.) to Regular Swimming Exercise II. Metabolism. Muscle Phospholipid Fatty Acid Composition and Lipid Peroxide Status. Poult. Fish. Wild Sci. 1 (2), 106-111.

VDLUFA-Methodenbuch III, 2006. 6. Ergänzung 2006, Zearalenon 16.9.2. VDLUFA-Verlag Darmstadt, Germany.

Vlata, Z., Porichis, F., Tzanakakis, G., Tsatsakis, A., Krambovitis, E., 2006. A study of zearalenone cytotoxicity on human peripheral blood mononuclear cells. Toxicol. Lett. 165, 274-281. 
Weis, J.S., 2014. Delayed behavioral effects of early life toxicant exposures in aquatic biota. Toxics 2, 165-187.

Wiesner, I.S., Rawnsley, H.M., Brooks, F.P., Senior, J.R., 1965. Sorbitol dehydrogenase in the diagnosis of liver disease. Dig. Dis. Sci. 10 (2), 147-151.

Woźny, M., Brzuzan, P., Gusiatin, M., Jakimiuk, E., Dobosz, S., Kuźmiński, H., 2012. Influence of zearalenone on selected biochemical parameters in juvenile rainbow trout (Oncorhynchus mykiss). Pol. J. Vet. Sci. 15 (2), 221-225.
Woźny, M., Dobosz, S., Obremski, K., Hliwa, P., Gomułka, P., Łakomiak, A., Różyński, R., Zalewski, T., Brzuzan, P., 2015. Feed-borne exposure to zearalenone leads to advanced ovarian development and limited histopathological changes in the liver of premarket size rainbow trout. Aquaculture 448, 71-81. 